\section{Pacific Northwest}

National Laboratory

Operated by Battelle for the

U.S. Department of Energy

\title{
FRAMES User Defined Body Burden Concentration File Module
}

\author{
M. A. Pelton \\ F. C. Rutz \\ M.A. Eslinger \\ G. M. Gelston
}

June 2001

Prepared for the U.S. Department of Energy

under Contract DE-AC06-76RL01830 


\title{
DISCLAIMER
}

This report was prepared as an account of work sponsored by the U.S. Environmental Protection Agency. Neither Battelle Memorial Institute, nor any of their employees, makes any warranty, express or implied, or assumes any legal liability or responsibility for the accuracy, completeness, or usefulness of any

information, apparatus, product, or process disclosed, or represents that its use would not infringe privately owned rights. Reference herein to any specific commercial product, process, or service by trade name, trademark, manufacturer, or otherwise does not necessarily constitute or imply its endorsement, recommendation, or favoring by the United States Government or any agency thereof, or Battelle Memorial Institute. The views and opinions of authors expressed herein do not necessarily state or reflect those of the United States Government or any agency thereof.

\author{
PACIFIC NORTHWEST NATIONAL LABORATORY \\ operated by \\ BATTELLE \\ for the \\ UNITED STATES DEPARTMENT OF ENERGY \\ under Contract DE-AC06-76RLO 1830
}

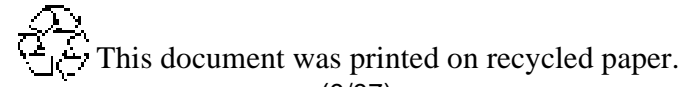


FRAMES User Defined Body Burden Concentration File Module Documentation
M. A. Pelton
G. M. Gelston
F.C. Rutz
M.A. Eslinger

June 2001

Prepared by the

U.S. Army Research and Development Center

Waterways Experiment Station

U.S. Army Corps of Engineers

Vicksburg, Mississippi 39180 


\section{Contents}

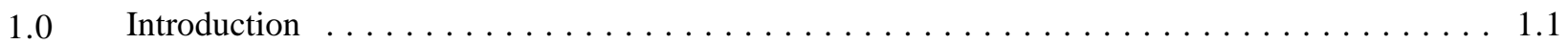

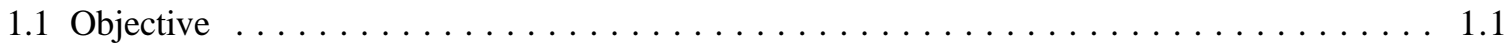

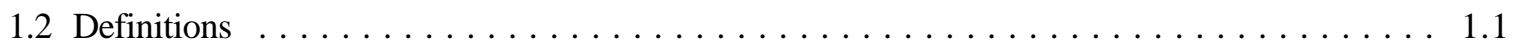

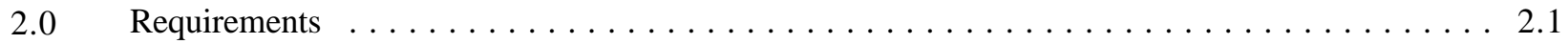

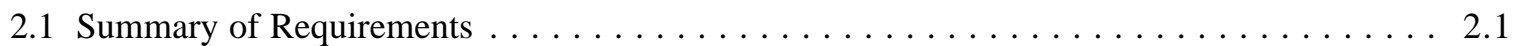

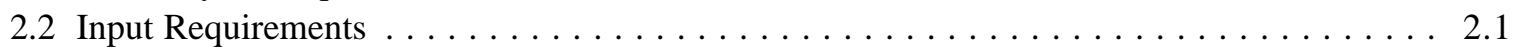

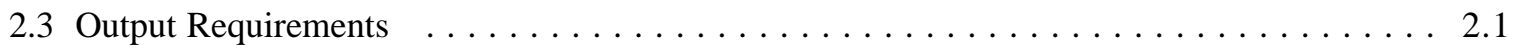

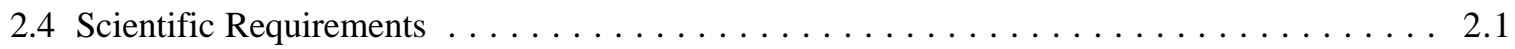

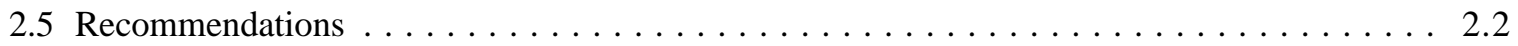

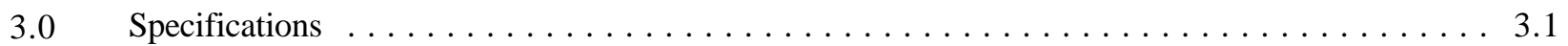

$4.0 \quad$ Test Plan Approach and Internal Testing Results $\ldots \ldots \ldots \ldots \ldots \ldots \ldots \ldots \ldots \ldots \ldots \ldots .1$

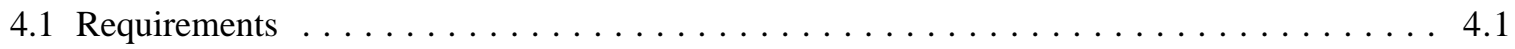

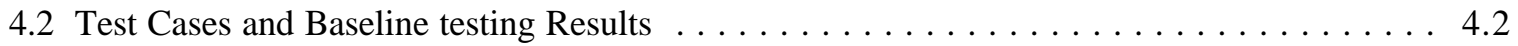

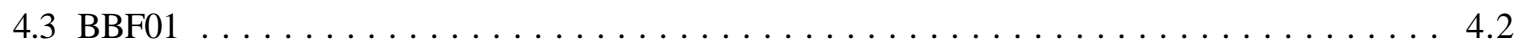

4.3.1 Description and Rationale $\ldots \ldots \ldots \ldots \ldots \ldots \ldots \ldots \ldots \ldots \ldots \ldots \ldots \ldots \ldots \ldots \ldots \ldots .2$

4.3 .2 Input Data . . . . . . . . . . . . . . . . . . . . . . . 4.2

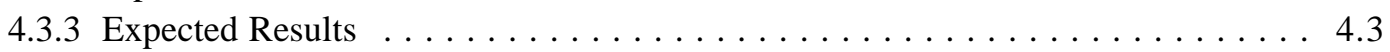

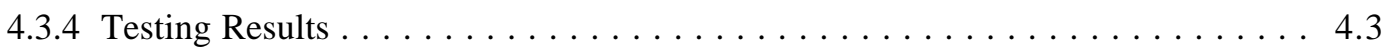

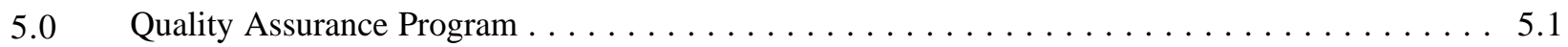

$6.0 \quad$ Reference $\ldots \ldots \ldots \ldots \ldots \ldots \ldots \ldots \ldots \ldots \ldots \ldots \ldots \ldots \ldots \ldots \ldots \ldots$

Appendix A- General Procedure for Test Case Implementation $\ldots \ldots \ldots \ldots \ldots \ldots \ldots \ldots \ldots$ A.1

\section{Figures}

5.1 Ensuring Quality in the Environmental Software Development Process $\ldots \ldots \ldots \ldots \ldots \ldots \ldots$

5.2 Quality Assurance Implementation Checklist for the FRAMES Technology

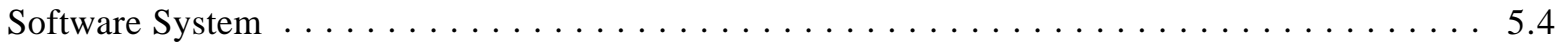

\section{Tables}

4.1 Testing Requirements for the Body Burden Concentration File $\ldots \ldots \ldots \ldots \ldots \ldots \ldots \ldots \ldots .1$ 
5.1 Relationship of PNNL Environmental Software Development Process to

Quality Assurance Requirements $\ldots \ldots \ldots \ldots \ldots \ldots \ldots \ldots \ldots \ldots \ldots \ldots \ldots \ldots$ 


\subsection{Introduction}

The Framework for Risk Analysis in Multimedia Environmental Systems (FRAMES) Body Burden Concentration File (BBF) contains time-varying, instantaneous, constituent concentrations for body burden by contaminant. This report contains the requirements for this file and will be used by software engineers and testers to ensure that the file inputs properly. A test plan will be developed from this document. Test cases will be developed from the test plan to ensure that the product meets the needs of the client(s) and to establish a baseline version of the file.

\subsection{Objective}

The purpose of the FRAMES BBF is to allow the user to input user-defined aquatic body burdens to generate the appropriate FRAMES data files to be used by fate and transport and exposure modules. Both radionuclides and chemicals can be input into this module. These constituent concentrations are used to describe the amount of contaminant present in the body. The constituent concentrations are time varying, and the user must define the time steps required.

\subsection{Definitions}

! Requirement: Characteristics and behaviors that a piece of software must possess to function adequately for its intended purpose. A good requirement is also testable. Sometimes a function is called a requirement, although it is not related to a regulatory definition.

! Design: A design is a comprehensive description of how a piece of software will function (i.e., how it will meet its requirements).

! Specifications: Specifications are a detailed description of an interface to a computer program or set of subroutines such that another programmer could develop a program, which would make proper use of the subroutines.

! Model/Code: Loosely defined herein to represent the software product for simulating an aspect associated with the release, fate $\&$ transport, exposure, intake, or risk/hazard of chemicals released into the environment; however, a model/code can simulate any phenomenon and is not limited to hazardous waste site assessments.

! Module: Model/Code and accompanying 1) pre- and post-processors for communicating with other models, databases, frameworks, etc., and 2) model-specific user interfaces (MUIs).

! System or Framework: Loosely defines a grouping of models, modules, databases, processors, or combination.

! Testable: Refers to the property of having the capability to examine and interrogate, such that a clear and concise conclusion can be drawn. 


\subsection{Requirements}

Requirements are characteristics and behaviors that a piece of software must possess to function adequately for its intended purpose. This section provides an overall summary of the requirements for the FRAMES BBF. Detailed requirements are described in the sections that follow.

\subsection{Summary of Requirements}

This section provides an overall summary of the requirements for the FRAMES BBF. Detailed requirements are described in the sections that follow.

The FRAMES BBF will:

1) Allow user to input time-varying, instantaneous, constituent concentrations for body burden by contaminant.

2) Allow unlimited species, constituents, progeny, concentrations.

3) Operate under Windows 95 and have a user-friendly interface with a standard windows look and feel.

4) For all input parameters having dimensions associated with them, the MUI will provide users with a choice of units.

5) Produce BBF following the FRAMES datafile specifications.

\subsection{Input Requirements}

The user will enter the input data required for the FRAMES User-Defined Body Burden Module via the Module User Interface (MUI). The MUI will allow the user to define the source problem and associated data. The main input to the FRAMES User-Defined Body Burden Module MUI is the timevarying, contaminant concentrations.

The data requirements for the Body Burden Concentration category are:

1) Usage location

2) Specie name

3) User-defined, time-varying, instantaneous contaminant mass concentrations for each contaminant.

\subsection{Output Requirements}

The FRAMES User-Defined Body Burden Module is required to output time-varying, contaminant concentrations for body burden. These outputs must meet the specifications of FRAMES (Whelan et al. 1997).

\subsection{Scientific Requirements}


The FRAMES BBF does not conduct computations that change the values input by the user except to convert units to internal FRAMES units. This is done by the MUI. No other scientific requirements exist for this Module.

\subsection{Recommendations}

1) The MUI will have online help in an HTML format that provides users with an easy-to-understand description of all input parameters required by the MUI, as well as an About tab to inform the user of the module title, version number, and brief description.

2) The MUI will include a reference feature in which the source of the specified value for each input item can be referenced if the user desires.

3) The MUI will show the range of values allowed for each input data item, when the cursor is positioned on that item, as a message at the bottom of the screen will appear. When an out-of-range value is entered in a field, the MUI will indicate this by a red background in the input field and an error message in addition to the allowed range message. Data input values within range are shown with a green field background. 


\subsection{Specifications}

The concentrations are in $\mathrm{pCi} / \mathrm{kg}$ or $\mathrm{mg} / \mathrm{kg}$, depending on whether the constituent is a radionuclide or a chemical. These concentration values are the instantaneous values at that time, not an average at the location specified. There are NO limits on the number of species, constituents, progeny, or concentrations. The following outline is a description of the basic information important to the BBF. An example BBF is included after the outline. Comparing the line-by-line description in the outline to the example should clarify and help locate data contained in the BBF. Lines beginning with ';' are descriptive comments only and will not appear in the actual BBF.

\section{BBF File Specification}

For each 'Module' a line with:

Module Name -(string)

Number of Lines that follow for this module's section

A line with:

Number of Header Lines -(integer)

For each 'Header Line' a line with:

Header line information -(string)

Next 'Header Line'

A line with:

Number of Data Sets -(integer)

For each 'Data Set' a line with:

Data Set name -(string)

; "All" / "eco\#"

; where 'eco' is the module type and '\#' is the id number

Usage Location Type -(string)

; "All" / "Eco Concentrations" / "Exposure Pathways" / any glyph type...

Number of Species -(integer)

For each 'Specie' a line with:

Species Name -(string)

Number of Constituents -(integer)

For each 'Constituent' a line with:

Constituent Name -(string)

Constituent ID -(string)

Time units -(string) - "yr"

Concentration units -(string) - "mg/kg"

Number of Time concentrations pairs -(integer)

Number of progeny -(integer)

For each 'Time Concentration Pair' a line with:

Time -(float)

Concentration -(float)

Next 'Time-Concentration Pair'

For each 'Progeny' a line with:

Progeny Name -(string)

Progeny ID -(string)

Time units -(string) - "yr" 


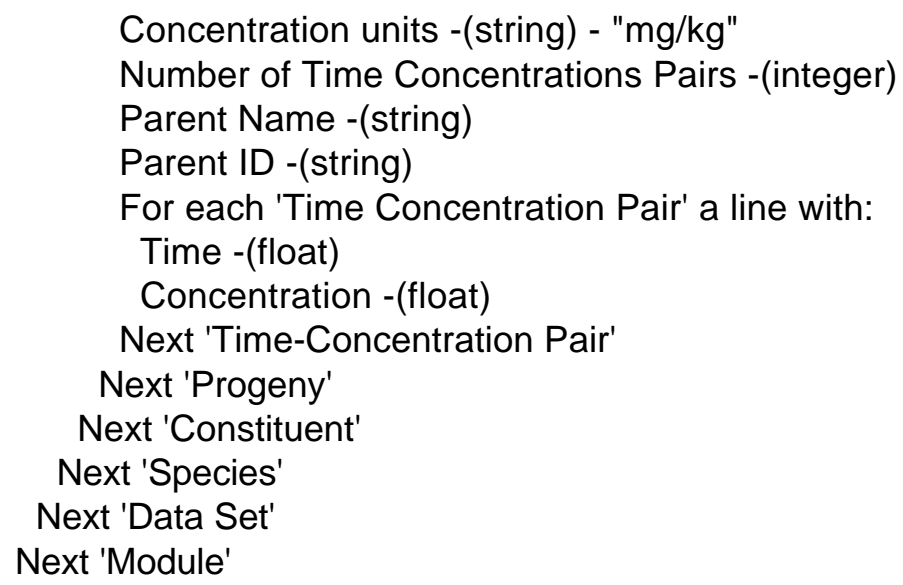

Example BBF Data File

"eco3",0000000096

1

"eco3 has known concentration values."

3

"efx5","efx5",2,3

"Diporeia spp.",2

"Benzene","71432","yr","mg/kg",2,0

$1.0,1.0$

2.0,2.0

"STRONTIUM-90","SR90", "yr","pCi/kg",2,1

$1.0,1.0$

2.0,2.0

"YTTRIUM-90","Y90","yr","pCi/kg",2,"STRONTIUM-90","SR90"

$1.0,1.0$

2.0,2.0

"Phalacrocorax penicillatus",2

"Benzene","71432","yr","mg/kg",2,0

5.0,7.0

$6.0,7.0$

"STRONTIUM-90","SR90","yr","pCi/kg",2,1

5.0,7.0

$6.0,7.0$

"YTTRIUM-90","Y90","yr","pCi/kg",2,"STRONTIUM-90","SR90"

$5.0,7.0$

$6.0,7.0$

"Corbicula fluminea",2

"Benzene","71432","yr","mg/kg",2,0

3.0,4.0

$4.0,4.0$ 
"STRONTIUM-90","SR90","yr","pCi/kg",2,1

3.0,4.0

$4.0,4.0$

"YTTRIUM-90","Y90","yr","pCi/kg",2,"STRONTIUM-90","SR90"

3.0,4.0

$4.0,4.0$

"efx7","efx7",2,3

"Diporeia spp.",2

"Benzene","71432","yr","mg/kg",2,0

$1.0,1.0$

2.0,2.0

"STRONTIUM-90","SR90","yr","pCi/kg",2,1

$1.0,1.0$

2.0,2.0

"YTTRIUM-90","Y90","yr","pCi/kg",2,"STRONTIUM-90","SR90"

$1.0,1.0$

2.0,2.0

"Phalacrocorax penicillatus",2

"Benzene","71432","yr","mg/kg",2,0

$5.0,6.0$

$6.0,6.0$

"STRONTIUM-90","SR90","yr","pCi/kg",2,1

$5.0,6.0$

$6.0,6.0$

"YTTRIUM-90","Y90","yr","pCi/kg",2,"STRONTIUM-90","SR90"

$5.0,6.0$

$6.0,6.0$

"Corbicula fluminea",2

"Benzene","71432","yr","mg/kg",2,0

$5.0,7.0$

7.0,7.0

"STRONTIUM-90","SR90","yr","pCi/kg",2,1

$5.0,7.0$

$7.0,7.0$

"YTTRIUM-90","Y90",,yr","pCi/kg",2,"STRONTIUM-90",,SR90"

$5.0,7.0$

$7.0,7.0$

"efx 8 ","efx 8 ",2,3

"Diporeia spp.",2

"Benzene","71432","yr","mg/kg",2,0

$1.0,1.0$

2.0,2.0

"STRONTIUM-90","SR90","yr","pCi/kg",2,1

$1.0,1.0$

2.0,2.0

"YTTRIUM-90","Y90","yr","pCi/kg",2,"STRONTIUM-90","SR90" 
$1.0,1.0$

2.0,2.0

"Phalacrocorax penicillatus",2

"Benzene","71432","yr","mg/kg",2,0

8.0,9.0

$9.0,9.0$

"STRONTIUM-90","SR90","yr","pCi/kg",2,1

$8.0,9.0$

$9.0,9.0$

"YTTRIUM-90","Y90","yr","pCi/kg",2,"STRONTIUM-90","SR90"

$8.0,9.0$

$9.0,9.0$

"Corbicula fluminea",2

"Benzene","71432","yr","mg/kg",2,0

$3.0,4.0$

4.0,4.0

"STRONTIUM-90","SR90","yr","pCi/kg",2,1

$3.0,4.0$

$4.0,4.0$

"YTTRIUM-90","Y90","yr","pCi/kg",2,"STRONTIUM-90","SR90" $3.0,4.0$

$4.0,4.0$ 


\subsection{Test Plan Approach and Internal Testing Results}

This paper presents a test plan and the baseline testing results for the FRAMES BBF. The purpose of the FRAMES BBF is to allow the user to input user-defined body burdens to generate the appropriate FRAMES data files to be used by fate and transport and exposure modules. Both radionuclides and chemicals can be input into this module. These constituent concentrations are used to describe the amount of contaminant present in the body. The constituent concentrations are time varying, and the user must define the time steps required. FRAMES is a platform that allows various multimedia modules to be linked into complete transport/exposure assessment systems (Whelan et al. 1997).

The BBF is being baseline tested for FRAMES Version 1.3. The suite of test cases developed for this testing, and presented in this paper, will also be used to assess the effects of future code modifications. Each time a modification is made to the program code, these test cases are rerun, and their results are compared to the previous run (regression testing). Changes in the results are evaluated to determine if they were expected due to the modification and were acceptable, or if they were an unintended side effect. In the latter case, the program code can be changed and the testing performed again.

\subsection{Requirements}

Requirements for the BBF are described in the paper entitled, Requirements for the FRAMES Body Burden Concentration File. These requirements have been reworded into the following list (Table 4.1) of concise, fundamental requirements suitable for testing.

Table 4.1. Testing Requirements for the Body Burden Concentration File

\begin{tabular}{|c|l|}
\hline $\begin{array}{c}\text { Requirement } \\
\text { Number }\end{array}$ & \multicolumn{1}{c|}{ General MUI Requirements } \\
\hline 1 & $\begin{array}{l}\text { The MUI will operate in Windows 95 and have a user-friendly interface with a } \\
\text { standard Windows look and feel. }\end{array}$ \\
\hline 2 & $\begin{array}{l}\text { The MUI will have online help in an HTML format that provides users with an } \\
\text { easy-to-understand description of all input parameters required by the MUI. }\end{array}$ \\
\hline 3 & $\begin{array}{l}\text { Each module will contain an About tab to inform the user of the module title, } \\
\text { version number, and brief description. }\end{array}$ \\
\hline 4 & $\begin{array}{l}\text { For all input parameters having dimensions associated with them, the MUI will } \\
\text { provide users with a choice of units. }\end{array}$ \\
\hline 5 & $\begin{array}{l}\text { The MUI will include a reference feature in which the source of the specified } \\
\text { value for each input item can be referenced if the user desires. }\end{array}$ \\
\hline 6 & $\begin{array}{l}\text { The MUI must allow the user to input all the required data to execute the } \\
\text { module. }\end{array}$ \\
\hline 7 & Allow unlimited species, constituents, progeny, concentration, or media. \\
\hline 8 & Produce BBE following the ERAMES datafile specifications. \\
\hline
\end{tabular}




\begin{tabular}{|c|l|}
\hline & \multicolumn{1}{c|}{ Output Requirements for the BBF } \\
\hline 9 & $\begin{array}{l}\text { Write Time-varying, instantaneous, constituent concentration for body burdens } \\
\text { to a file in the specified FRAMES format. }\end{array}$ \\
\hline
\end{tabular}

\begin{tabular}{|l|l|}
\hline 10 & \multicolumn{1}{c|}{ Scientific Requirements } \\
\hline & $\begin{array}{l}\text { The BBF does not conduct computations that change the values input by the } \\
\text { user except to convert units to internal FRAMES units. This is done by the } \\
\text { MUI. }\end{array}$ \\
\hline
\end{tabular}

\subsection{Test Cases and Baseline Testing Results}

This section describes the specific test case used for baseline testing of the FRAMES User

Defined BBF Module. Appendix A describes the general procedure for conducting the test.

\subsection{BBF01}

\subsubsection{Description and Rationale}

The purpose of this case is to test if the module correctly requests and transfers all necessary data to complete a BBF file. The MUI should be checked to ensure that it handles unit conversions adequately and also that user input-data are checked for errors.

\subsubsection{Input Data}

Set up a case using Appendix A. Name the file BBF01.gid.

For the contaminants, select ANTIMONY-125, Benzene, and Phenol. For the species, choose Rainbow Trout.

Enter these times and concentrations on the User Input screen for the BBF.

Antimony 125

\begin{tabular}{|c|c|}
\hline Time $(\mathrm{yr})$ & Units $(\mathrm{Ci} / \mathrm{g})$ \\
\hline 0 & .1 \\
\hline 1 & .2 \\
\hline 2 & .3 \\
\hline 5 & 1 \\
\hline
\end{tabular}


Tellurium $125 \mathrm{M}$

\begin{tabular}{|c|c|}
\hline Time $(\mathrm{yr})$ & Units $(\mathrm{pCi} / \mathrm{kg})$ \\
\hline 0 & 0 \\
\hline 5 & 23 \\
\hline 45 & .598 \\
\hline 56 & 15 \\
\hline
\end{tabular}

Benzene

\begin{tabular}{|c|c|}
\hline Time $(\mathrm{hr})$ & Units $(\mathrm{g} / \mathrm{kg})$ \\
\hline 0 & .3 \\
\hline 24 & .4 \\
\hline 48 & .5 \\
\hline
\end{tabular}

Phenol

\begin{tabular}{|c|c|}
\hline Time (day) & Units $(\mathrm{g} / \mathrm{g})$ \\
\hline 0 & 10 \\
\hline 1 & .321 \\
\hline 365 & .5 \\
\hline
\end{tabular}

After save and exiting and error checking, right click again on User Input and enter different numbers for the concentrations, testing how the MUI handles spaces, out of sequence fluxes, etc.

\subsubsection{Expected Results}

The expected results for this test case will be that it creates a BBF in accordance with the FRAMES specifications. It is expected that the MUI will be easy to use, have a functionality consistent with standard Windows software and that the online help will be clear and consistent. It is expected that the MUI will request only the necessary information.

It is expected that both radionuclides and chemicals can be input. It is expected that the transfer of data from the MUI to the BBF will occur properly and that any necessary unit conversions will be done correctly. The transfer of data between files can be confirmed by visual inspection of these files (test01.bbf). It is expected that the MUI will not continue until all data have been entered completely and within the correct specifications shown in the scrollbar and the online help. If data entered are incorrect or incomplete, an error message should appear.

\subsubsection{Testing Results}


The MUI performed as expected by only requesting necessary information and allowing all required data to be input, and returned correct error messages. It was easy to use with Windows interface, it allowed chemicals and radionuclides to be input, and the transfer of data from the MUI to the BBF occurred properly with the necessary unit conversions. Note that although the MUI will convert the dimensions of user input data values into the units needed by the model, the MUI will always display the approximate value and units in which the user originally entered each input data item. The About tab showed information, and a choice of units was available for all parameters. The Body Burden concentration was in the output. The reference feature worked as expected.

Although radionuclides are not handled by the ERED database, they can be input in the contaminant database. So the BBF received radionuclides and chemicals and appeared to function properly with both and with progeny.

There was no help file or F1 attached. Also, there were no colored boxes for the input screen. Recommend help file and colored boxes for acceptable range. Also recomend entry in the help file referring to no blank lines in data entry as all data below the blank line is deleted. 


\subsection{Quality Assurance Program}

Updates to the FRAMES technology software system will be developed under a quality assurance program documented in Gelston et al. (1998). Quality is defined as the capability of the software to meet client needs. Meeting client needs starts with a shared understanding of how the software must perform and continues throughout the software life cycle of design, development, testing, and implementation through attention to details.

Figure 5.1 outlines the software-development process that will be used for the FRAMES technology software system highlighting the quality check points. The FRAMES technology software system activities flow down the left side of Figure 6.1 because it is software developed for the first time as opposed to a modification to existing software. The process shown is designed for compatibility with similar processes used by other government agencies. For example, this quality process compares favorably with that in EPA Directive 2182, System Design and Development Guidance (EPA 1997). It also compares favorably with the Office of Civilian Radioactive Waste Management's Quality Assurance Requirements and Description, Supplement I, Software (OCRWM 1995). Activities roughly equivalent across these processes are shown in Table 5.1.

Development of the FRAMES technology software system includes the implementation of a quality assurance checklist (see Figure 5.2). All team members understand the component requirements and design that are necessary to ensure quality. Completion of this checklist verifies that all documentation will be complete for transfer of the software to client use. 


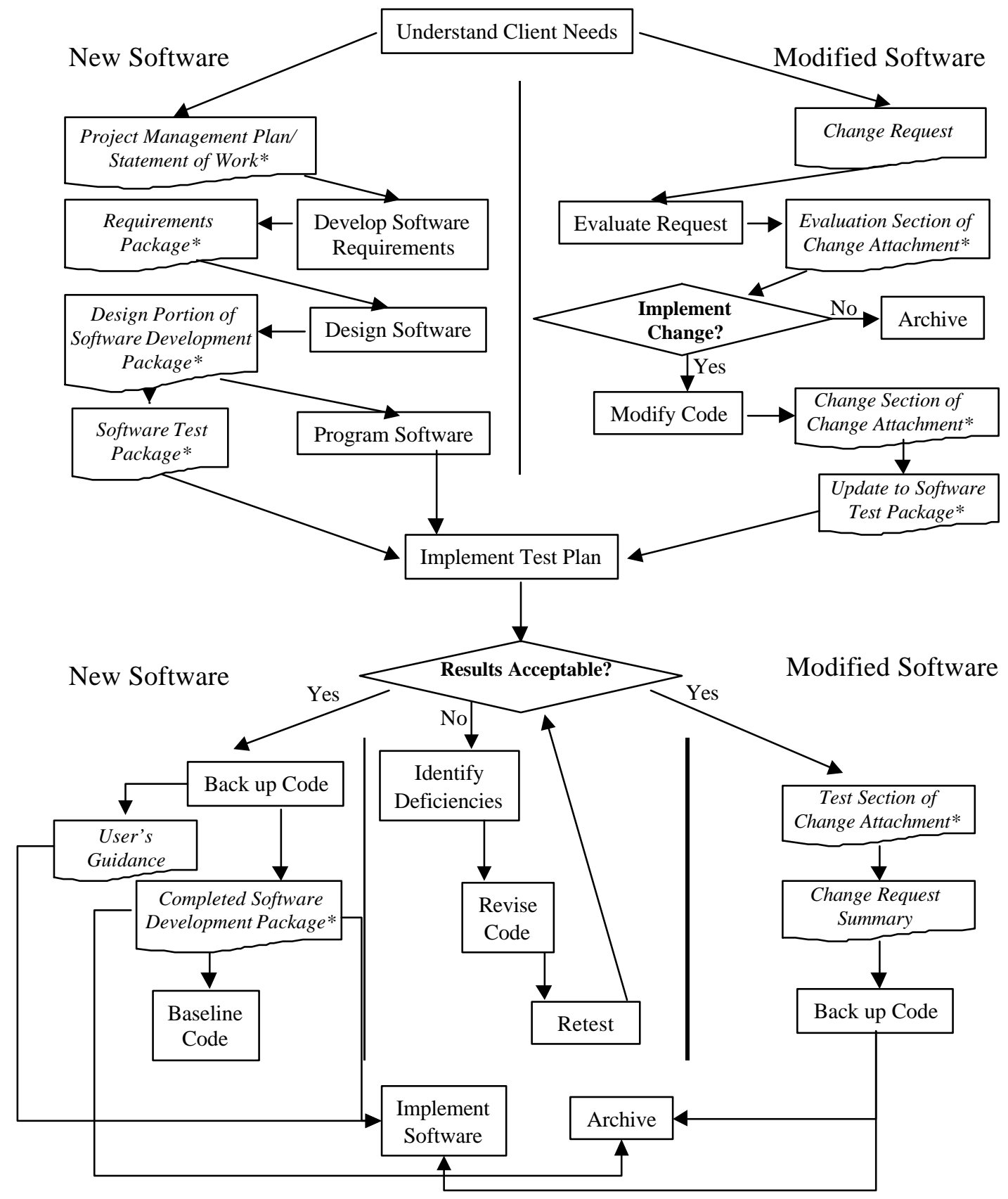

Figure 5.1. Ensuring Quality in the Environmental Software Development Process 
Table 5.1. Relationship of PNNL Environmental Software Development Process to Quality Assurance Requirements (OCRWM 1995, EPA 1997)

\begin{tabular}{|c|c|c|}
\hline \multirow[t]{2}{*}{$\begin{array}{l}\text { OCRWM Quality Assurance } \\
\text { Requirement }^{(\text {a) }}\end{array}$} & $\begin{array}{l}\text { EPA Essential Element of } \\
\text { Information }^{(\mathbf{b})}\end{array}$ & $\begin{array}{l}\text { Environmental Software } \\
\text { Process Equivalent } \\
\text { (Section) }\end{array}$ \\
\hline & 4-System Implementation Plan & $\begin{array}{l}\text { Project Management Plan } \\
\text { or Statement of Work }\end{array}$ \\
\hline $\begin{array}{l}\text { I.2.5A Functional Requirements } \\
\text { Information Documentation; I.2.5C } \\
\text { Requirements and Design } \\
\text { Documentation }\end{array}$ & $\begin{array}{l}\text { 5-System Detailed } \\
\text { Requirements Document }\end{array}$ & Requirements Package \\
\hline $\begin{array}{l}\text { I.2.1 Software Life Cycles, } \\
\text { Baselines (see their Appendix C), } \\
\text { and Controls }\end{array}$ & 6-Software Management Plan & $\begin{array}{l}\text { Project Management Plan } \\
\text { or Statement of Work and } \\
\text { Gelston et al. (1998) }\end{array}$ \\
\hline $\begin{array}{l}\text { I.2.2 Software Verification }{ }^{(\mathrm{c})} \text { and } \\
\text { Software Validation; } \\
\text { I.2.4 Software Validation }^{(\mathrm{d})}\end{array}$ & $\begin{array}{l}\text { 7-Software Test and } \\
\text { Acceptance Plan }\end{array}$ & Software Test Package \\
\hline $\begin{array}{l}\text { I.2.3 Software Verification; } \\
\text { I.2.5C Requirements and Design } \\
\text { Information Documentation }\end{array}$ & 8-Software Design Document & $\begin{array}{l}\text { Design Portion of Software } \\
\text { Development Package }\end{array}$ \\
\hline I.2.6A Configuration Identification & & Completed Software \\
\hline \multirow[t]{2}{*}{$\begin{array}{l}\text { I.2.6B Configuration Control; } \\
\text { I.2.6C Configuration Status; I.2.7 } \\
\text { Defect Reporting and Resolution }^{(\mathrm{e})}\end{array}$} & $\begin{array}{l}\text { 9-Software Maintenance } \\
\text { Document }\end{array}$ & Modification Documentation \\
\hline & $\begin{array}{l}\text { 10-Software Operations } \\
\text { Document }\end{array}$ & $\begin{array}{l}\text { User's Guidance and } \\
\text { Training }\end{array}$ \\
\hline \multirow[t]{2}{*}{$\begin{array}{l}\text { I.2.5B User Information } \\
\text { Documentation }\end{array}$} & $\begin{array}{l}\text { 11-Software User's Reference } \\
\text { Guide }\end{array}$ & $\begin{array}{l}\text { User's Guidance and } \\
\text { Training }\end{array}$ \\
\hline & 12-System Integration Test & Software Test Package \\
\hline \multicolumn{3}{|c|}{$\begin{array}{l}\text { (a) Note that OCRWM requirement I.2.8, Control of the Use of Software, is the responsibility of the } \\
\text { OCRWM-related client. }\end{array}$} \\
\hline \multicolumn{3}{|c|}{ Agency before contract initiation with the project team. } \\
\hline \multicolumn{3}{|l|}{ (c) } \\
\hline \multicolumn{3}{|c|}{$\begin{array}{l}\text { (d) Validation includes testing by those other than the software engineers who developed the code to } \\
\text { provide an independent confirmation that software functions as required. } \\
\text { (e) Note that some changes requested by clients may not be made in the software unless funding has }\end{array}$} \\
\hline $\begin{array}{l}\text { (e) Note that some changes requeste } \\
\text { been allocated for such modifica }\end{array}$ & $\begin{array}{l}\text { by clients may not be made in the } \\
\text { ons. }\end{array}$ & ftware unless funding has \\
\hline
\end{tabular}




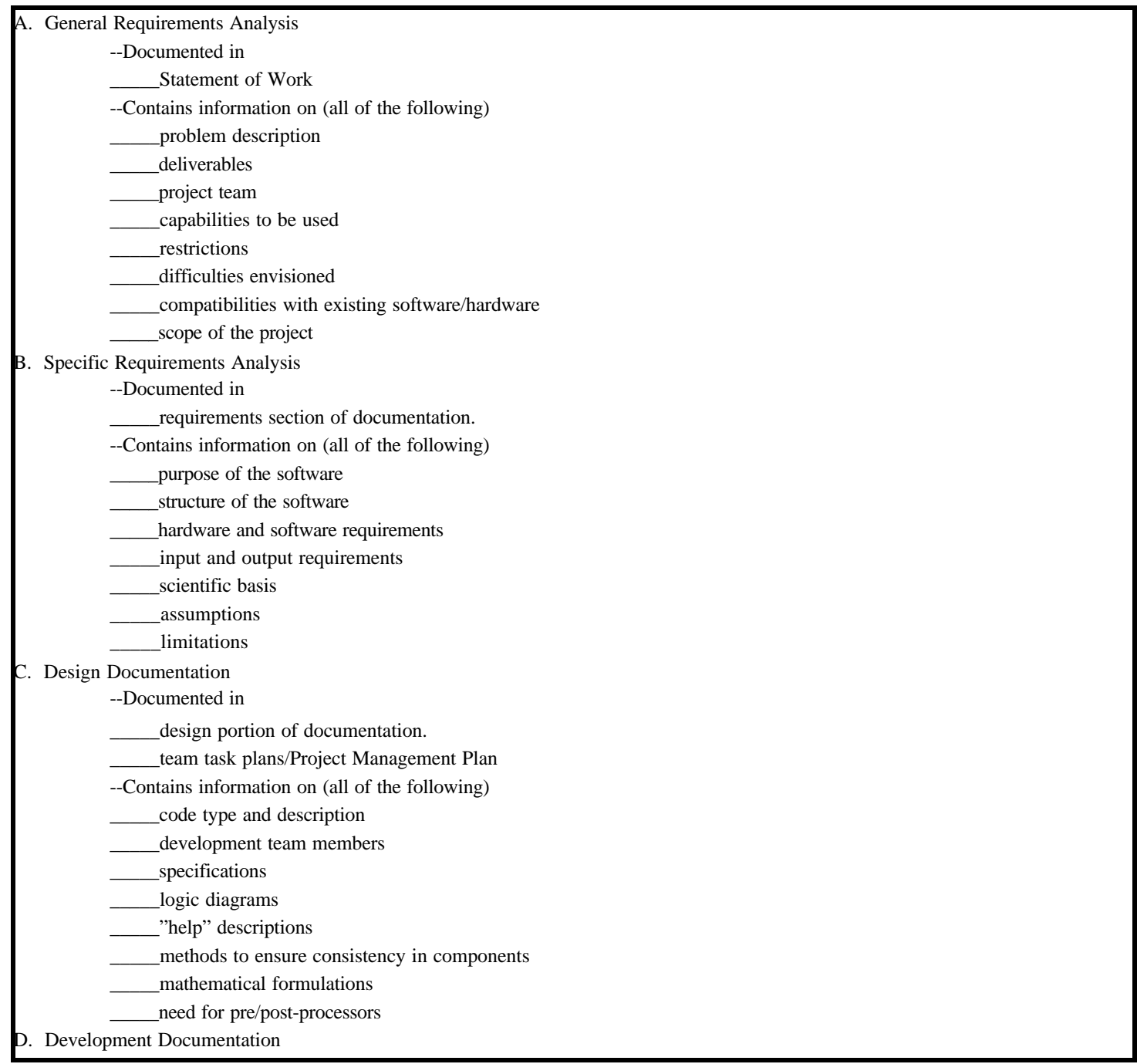

Figure 5.2. Quality Assurance Implementation Checklist for the FRAMES Technology Software System 


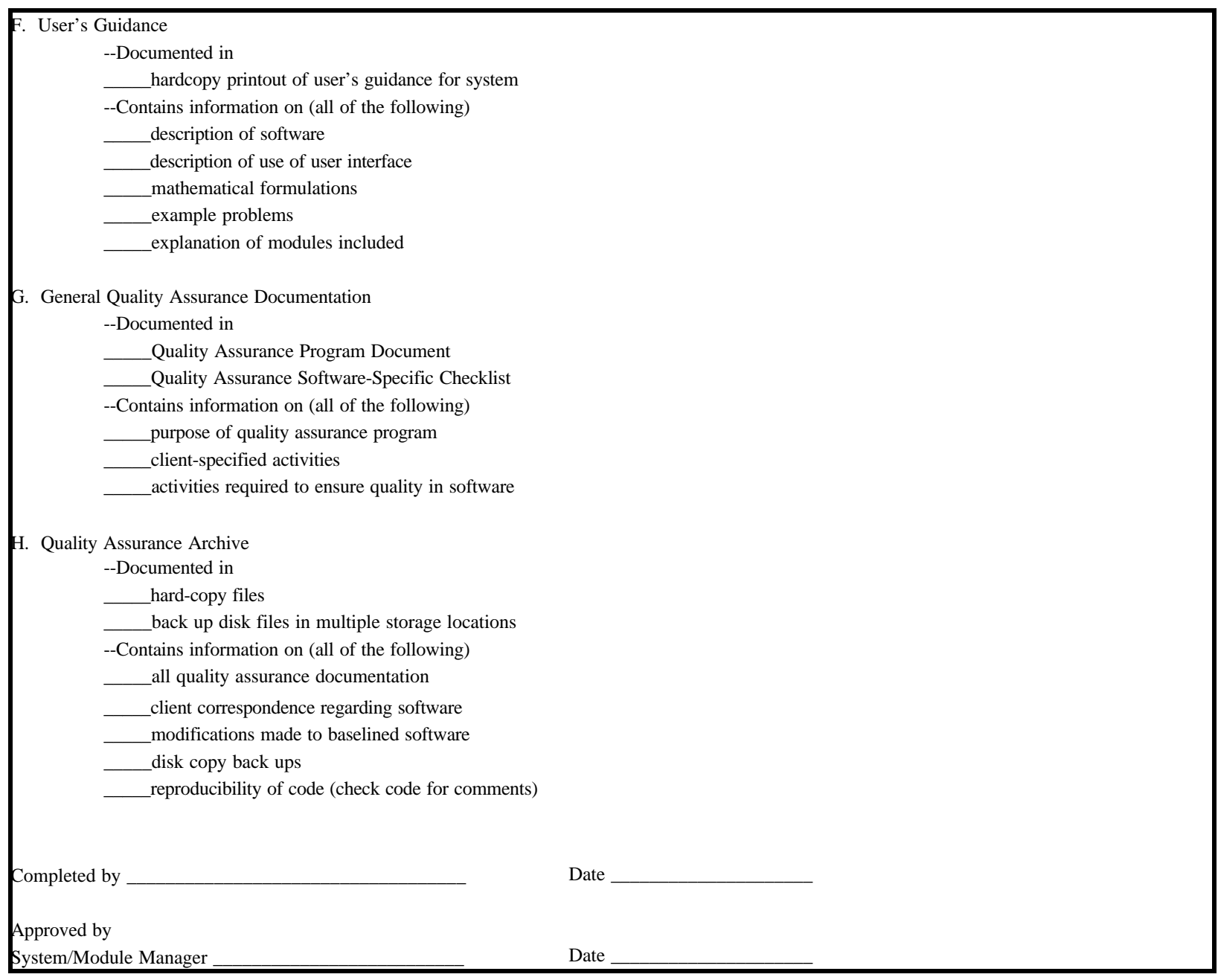

Figure 5.2. Quality Assurance Implementation Checklist for FRAMES Technology Software System (contd) 


\subsection{References}

Gelston, G. M., R. E. Lundgren, J. P. McDonald, and B. L. Hoopes. 1998. An Approach to Ensuring Quality in Environmental Software, PNNL-11880, Pacific Northwest National Laboratory, Richland, Washington.

Office of Civilian Radioactive Waste Management (OCRWM). 1995. Quality Assurance Requirements and Description, Supplement I, Software, U.S. Department of Energy, Washington, D.C.

U.S. Environmental Protection Agency (EPA). 1997. System Design and Development Guidance, EPA Directive Number 2182, Washington, D.C.

Whelan G., K. J. Castleton, J. W. Buck, G. M. Gelston, B. L. Hoopes, M. A. Pelton, D. L. Strenge, and R. N Kickert. 1997. Concepts of a Framework for Risk Analysis in Multimedia Environmental Systems (FRAMES). PNNL-11748,

Pacific Northwest National Laboratory, Richland, Washington. 
Appendix A

General Procedure for Test Case Implementation 


\section{Appendix A: General Procedure for Test Case Implementation}

Open the Multimedia Framework (fui.exe). Select New from the File menu. Enter a file name and select Open. Enter a site name at the prompt and select Ok.

Double click on the contaminant icon, ecological benchmark icon, ecological exposure icon, and ecological effects icon located on the toolbar. The icons will appear on the main screen. Click on each one and drag to the desired location on the screen, and then connect the icons together. To do this, hold down the shift key, click on an icon, and drag the mouse to the next icon. Release the mouse button and the shift key. A line will connect the two icons with an arrow pointing from the first icon clicked on to the second icon. To remove this line, repeat the steps used to connect it. Continue linking all icons together, moving from left to right across the screen so that the arrows are pointing in the right direction (see screen capture

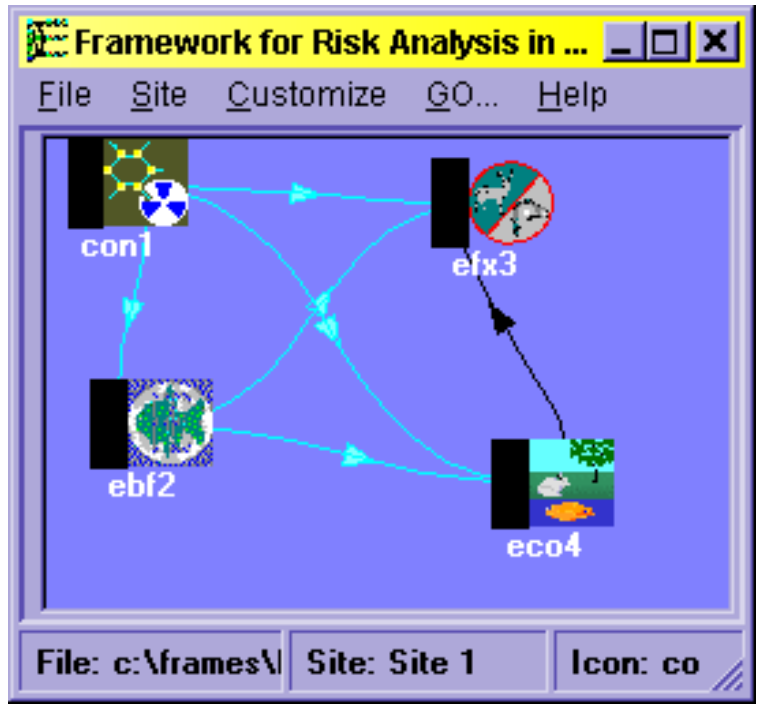
below). The icons need to be attached to another to show the flow of contamination. To remove an icon from the screen, right click on the icon and then select delete from the resultant pop-up menu. An icon can have more than one connection (i.e., the body-burden module can be connected to two different ecological-effects modules).

Right click on the contaminant icon and choose General Info. When the General Info screen opens, select the Label: Contaminants and Module: Framework for Risk Analysis in Multimedia Environmental Systems (FRAMES) Default Chemical Database Selection. Click on OK at the bottom of the screen; this returns you to the work area, and the signal light attached to the contaminant icon changes from black into red. Right click on the contaminant icon in the main screen and choose User Input on the menu that appears and the Contaminant Selection screen will open. Select from Possible Contaminants: All Contaminants.

Scroll to select the contaminants or use the Find option on this screen. Select File/'Save and Exit' to return to the work screen. The light will change from red to green.

Right click on the ecological benchmark icon you placed on the main screen and select General Info. When the General Info screen opens, choose Label: Eco Benchmark and Module: PNL ERED Database. Click OK. The signal will turn from black to red. Following the selection of the General Info option, right click on the eco logical benchmark icon and select User Input. Once the User Input selection is made, the ecological benchmark user login screen will be displayed. Enter your username and password into the login screen and click OK. Following the selection of the OK button, the user input screen for the ecological benchmark model will be displayed. Using the treeview control on the left of the user screen, enter all the required data into the interface selecting the rainbow trout as species of concern. Once the input data have been entered, click save and exit, and the light will turn from red to green.

Once the user-input data have been entered and saved for the ecological benchmark model, right click on the Eco Exposure icon and select General Info. When the General Info screen opens, choose Label: Known Body Burden and Module: FRAMES Body Burden Module. Click OK. The signal will turn from black to red. Following the selection of the General Info option, right click on the Body Burden model icon and select User Input. Once the 
User Input selection is made, the User-Defined Body Burden User Input screen will be displayed. Following the display of the user input screen, enter applicable data for all of the locations, species, and contaminants displayed within the screen. Once the data have been entered, click save and exit, and the light will turn from red to yellow. Right click again and select Run Model.

For each test case, follow the above steps. To view the results, select "View/Print Module Output" from the right click menu and select the desired viewer, or open the comma-separated BBF file found in the FRAMES directory. 